\title{
Academic adjustment among second year students in Malaysian universities
}

\begin{abstract}
Successful adjustment to college during the first year is an area of increasing concern for most institutions of higher education (Tinto, 1993). The transition from high school to university is a major life change for many adolescents. Entering university may mean getting new learning experiences and opportunities for psychosocial development. At the same time students may find university life stressful because of the increasing academic demands and the establishment of new social relations. Academic adjustment or how well students deal with educational demands, includes motivation to complete academic work, success in meeting academic requirements, academic effort and satisfaction with the academic environment (Baker \& Siryk, 2004). Previous studies have shown the relationship between several psychological factors with student adjustment in university which includes selfesteem (Friedlander, et.al., 2007) and emotional Intelligence (Summerfeldt, 2005). A study was conducted on 647 second year students in two public and two private universities in Malaysia to examine their level of adjustment in relation to several psychological variables namely self-esteem and emotional intelligence. Findings showed that the majority of respondents $(70.2 \%)$ have moderate level of adjustment indicating that students are not adjusting very well in university. Correlation analysis showed that there are positive and significant correlations between students' overall adjustment with self-esteem $(r=.52, \mathrm{p}<.05)$ and emotional intelligence $(\mathrm{r}=.39, \mathrm{p}<.05)$. Regression analysis revealed that self-esteem and emotional intelligence together contribute $27.5 \%$ of the variance in students' overall adjustment. The findings of the study will help to determine the relationship between the psychosocial variables mentioned with university students' level of adjustment. The implications of the findings are discussed in terms of learning in tertiary education.
\end{abstract}

Keyword: University students; Self-esteem; Emotional intelligence; Student adjustment 